\title{
Characterization of large cadmium zinc telluride crystals grown by traveling heater method
}

Chen, H.; Awadalla, S.A.; Iniewski, K.; Lu, P.H.; Harris, F.; Mackenzie, J.; Hasanen, T.; Chen, W.; Redden, R.; Bindley, G.

Total number of authors:

20

Published in:

Journal of Applied Physics

Link to article, DOI:

$10.1063 / 1.2828170$

Publication date:

2008

Document Version

Publisher's PDF, also known as Version of record

Link back to DTU Orbit

Citation (APA):

Chen, H., Awadalla, S. A., Iniewski, K., Lu, P. H., Harris, F., Mackenzie, J., Hasanen, T., Chen, W., Redden, R., Bindley, G., Kuvvetli, I., Budtz-Jørgensen, C., Luke, P., Amman, M., Lee, J. S., Bolotnikov, A. E., Camarda, G. S., Cui, Y., Hossain, A., \& James, R. B. (2008). Characterization of large cadmium zinc telluride crystals grown by traveling heater method. Journal of Applied Physics, 103(1), 014903. https://doi.org/10.1063/1.2828170

\section{General rights}

Copyright and moral rights for the publications made accessible in the public portal are retained by the authors and/or other copyright owners and it is a condition of accessing publications that users recognise and abide by the legal requirements associated with these rights.

- Users may download and print one copy of any publication from the public portal for the purpose of private study or research.

- You may not further distribute the material or use it for any profit-making activity or commercial gain

- You may freely distribute the URL identifying the publication in the public portal 


\title{
Characterization of large cadmium zinc telluride crystals grown by traveling heater method
}

\author{
H. Chen, S. A. Awadalla, ${ }^{a)}$ K. Iniewski, P. H. Lu, F. Harris, J. Mackenzie, T. Hasanen, \\ W. Chen, R. Redden, and G. Bindley \\ Redlen Technologies, Sidney, British Columbia V8L 5Y8, Canada
}

Irfan Kuvvetli and Carl Budtz-Jørgensen

Danish National Space Center, DK-2100 Copenhagen, Denmark

P. Luke, M. Amman, and J. S. Lee

Lawrence Berkeley National Laboratory, Berkeley, California 94720, USA

A. E. Bolotnikov, G. S. Camarda, Y. Cui, A. Hossain, and R. B. James

Brookhaven National Laboratory, Upton, New York 11793, USA

(Received 6 September 2007; accepted 2 November 2007; published online 3 January 2008)

The focus of this paper is to evaluate thick, $20 \times 20 \times 10$ and $10 \times 10 \times 10 \mathrm{~mm}^{3}$, cadmium zinc telluride $(\mathrm{CZT}), \mathrm{Cd}_{0.9} \mathrm{Zn}_{0.1} \mathrm{Te}$, crystals grown using the traveling heater method (THM). The phenomenal spectral performance and small size and low concentration of Te inclusions/precipitates of these crystals indicate that the THM is suitable for the mass production of CZT radiation detectors that can be used in a variety of applications. Our result also proves that with careful material selection using IR and high-quality fabrication processes, the theoretical energy resolution limit can be achieved. (C) 2008 American Institute of Physics. [DOI: 10.1063/1.2828170]

\section{INTRODUCTION}

To date, cadmium zinc telluride (CZT) has captured considerable interest due to its potential in many applications as a room temperature radiation detector. The application of CZT is very much thickness dependent. The typical thickness of CZT for detecting energy less than $200 \mathrm{keV}$ is usually $6 \mathrm{~mm}$ or less, which is adequate for applications such as $\mathrm{x}$-ray astronomy or gamma-camera imaging in nuclear medicine. However, applications in gamma spectroscopy, such as homeland security, require much thicker CZT to provide sufficient stopping power for high-energy gamma photons. Certainly, large-area CZT detectors with thicknesses of $10 \mathrm{~mm}$ or more have existed for several years ${ }^{1}$ but their availability and poor performance has limited their commercial deployment in the higher energy gamma application. Recently, it was shown that the traveling heater method (THM) is a practical approach to crystal growth supporting volume production of CZT radiation detectors for both medical imaging and homeland security applications., ${ }^{2,3}$ Large-area monolithic CZT detectors that are produced by THM method provide excellent performance. Thicker detectors ${ }^{2,3}$ have also been shown to function well. This level of performance has been restricted to smaller area single-channel detectors in the form of Frisch-Grid devices.

In this paper, we discuss the spectral response as well as electrical properties and various physical properties of the $20 \times 20 \times 10$ and $10 \times 10 \times 10 \mathrm{~mm}^{3}$ monolithic pixellated detectors.

\footnotetext{
${ }^{a)}$ Author to whom correspondence should be addressed. Electronic mail: salah.awadalla@redlen.com.
}

\section{SINGLE-CRYSTAL: LARGER AND THICKER}

The standard monolithic CZT detectors, $20 \times 20$ $\times 5 \mathrm{~mm}^{3}$, produced by our THM process have shown excellent singularity and spectral performance. An energy resolution, full width at half maximum (FWHM), of $<1 \%$ was measured on a virtual Frisch-Grid Device. ${ }^{2,3}$ However, for practical purposes, thicker detectors are needed in the higher energy gamma range such as gamma spectroscopy and standoff detection for homeland security. In parallel, larger area crystals are needed to ultimately provide the required larger volume. To meet this challenge and future ones, we have modified our THM process to grow $75 \mathrm{~mm}$ diameter ingots. Figure 1 shows the first THM grown $75 \mathrm{~mm}$ diameter CZT of which $80 \%$ is single crystals. We have also successfully produced near $100 \%$ single-crystal ingots. To demonstrate the $100 \%$ singularity of the ingot, one of the ingots is cut parallel to the growth direction, as shown in Fig. 2.

We have also increased the thickness of our postgrowth annealing process sliced wafers from 6 to $12 \mathrm{~mm}$ allowing the production of 10 -mm-thick detectors. Such scaling will

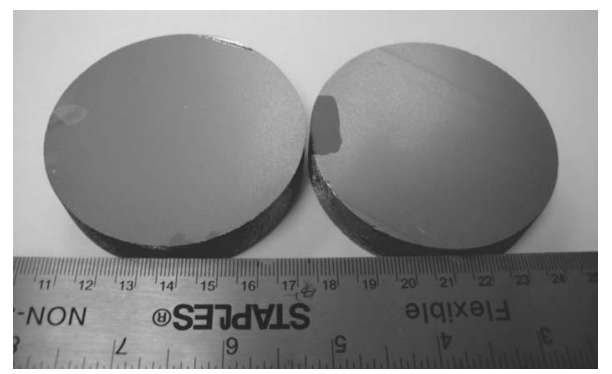

FIG. 1. Typical singularity $(\sim 80 \%)$ in the current Redlen $75 \mathrm{~mm}$ diameter THM CZT ingots. 


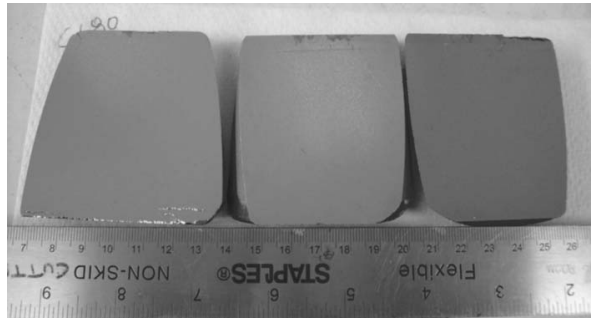

FIG. 2. $100 \%$ single crystals cut from a $75 \mathrm{~mm}$ diameter CZT ingot along the direction of their growth.

make it economically feasible to manufacture thick detectors an advancement that is essential for many applications, but especially for homeland security application.

\section{CRYSTAL CHARACTERIZATION}

\section{A. Te inclusion/precipitate study via IR microscopy and $\mathrm{x}$-ray topography mapping}

It has long been known that the presence of $\mathrm{Te}$ inclusions/precipitates in CZT crystals, especially defects of sizes larger than $10 \mu \mathrm{m}$ and of relatively high densities, can degrade detector performance. This deteriorating effect of Te inclusions/precipitates can be more severe in thicker CZT detectors. Among the most effective methods of detecting these crystal defects in CZT bulk materials are IR transmission microscopy and $\mathrm{x}$-ray topography.

Previously, a low concentration, typically much smaller than $10 \mu \mathrm{m}$ size, of Te inclusions/precipitates in THM CZT material has been reported in crystals cut from the standard $6 \mathrm{~mm}$ wafers. ${ }^{2,3}$ This characteristic is again measured in the postannealed $12 \mathrm{~mm}$ wafer materials. IR analysis, measured at LBNL, revealed a low density of precipitated/inclusion. The black dots in Fig. 3 represent the amount of Te precipitate/inclusion in the sample with particle size less than $5 \mu \mathrm{m}$. The advantages of small size, low concentration of Te inclusions/precipitates in CZT thick detectors have also been reported previously. ${ }^{2}$

It is important to mention that spatial resolution of the $\mathrm{x}$-ray mapping system plays a crucial role in this kind of study. By using low- and high-contrast $\mathrm{x}$-ray mappings, researchers at BNL have been able to reveal Te inclusions/ precipitates of sizes less than $5 \mu \mathrm{m}$ where they have seen under high-contrast only. Figures 4(a) and 4(b) shows an images for a $4 \times 4 \times 12 \mathrm{~mm}^{3}$ detector with low and high-

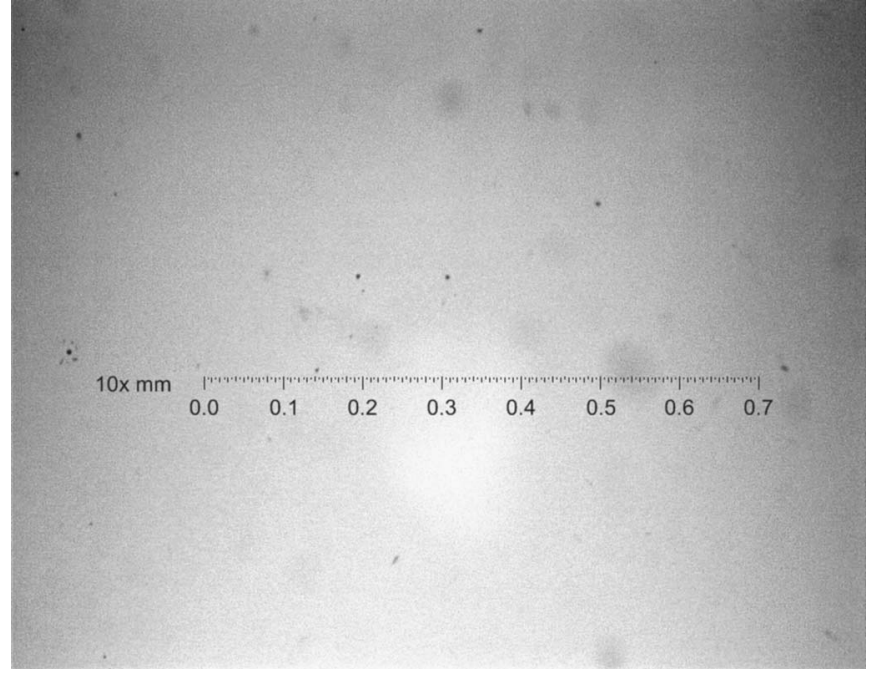

FIG. 3. Infrared transmission image of the 10-mm-thick crystal used in the alpha-particle mappings shown in Fig. 6.

contrast $\mathrm{x}$-ray mapping, respectively. The two images have been taken with $\sim 3 \mu \mathrm{m}$ resolution and $200 \times 200$ pixels. As is seen in the figure, the density of both Te precipitate/ inclusion and their sizes is very low too.

\section{B. Zinc uniformity mapping via room temperature photoluminescence}

To check the Zn uniformity, a $20 \times 20 \times 5 \mathrm{~mm}^{3}$ tile was cut and sent to the Canadian National Research Council (CNRC). Zn mapping was done using room temperature photoluminescence (PL). Photoluminescence scanning in the range of 740-860 nm was employed using a $12 \mathrm{~mW}$ with $532 \mathrm{~nm}$ laser source at a spatial resolution of $0.2 \mathrm{~mm}$. The samples were mounted so that the spectral maps could be referenced to an orientation-marked $V$ surface. In all of the maps, the $V$ edge surface is at the top of the figure (the $A$ face). The lower surface in all figures is the $B$ face. The back surface maps were flipped to correspond spatially with the upper surface ones. Each sample generated more than 10000 individual spectra from which maps were made of the equivalent $\mathrm{Zn}$ concentration in CZT using the expression given by Toney et al.: ${ }^{4}$

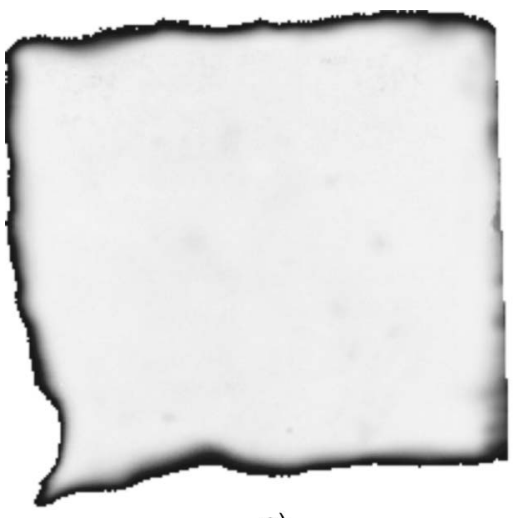

a)

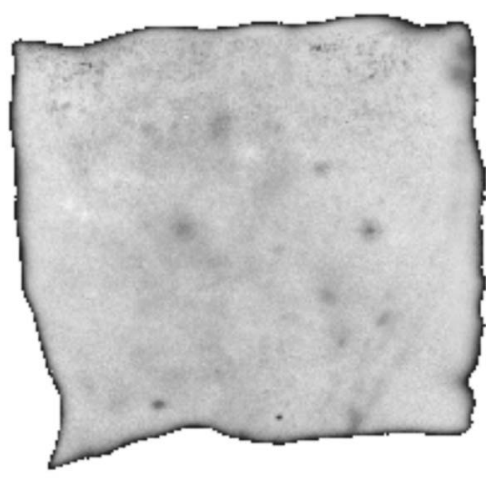

b)
FIG. 4. X-ray topography mappings of Te precipitate/ inclusion comparison: (a) low contrast and (b) high contrast. 
TABLE I. Zn content of standard CZT $20 \times 20 \times 5 \mathrm{~mm}^{3}$ samples performed at CNRC using room temperature PL mapping.

\begin{tabular}{lcc}
\hline \hline Sample & $\begin{array}{c}\text { Mol Zn\% } \\
\text { A face (ave) }\end{array}$ & $\begin{array}{c}\text { Mol Zn\% } \\
B \text { face (ave) }\end{array}$ \\
\hline MC41-46 & 10 & 9.8 \\
MC48-39 & 10 & 10.2 \\
MC42-39 & 10.2 & 10.2 \\
MC42-52 & 10.6 & 10 \\
\hline \hline
\end{tabular}

$$
E_{\text {peak }}=1.51+0.606 x+0.139 x^{2},
$$

where $E_{\text {peak }}$ is photopeak energy and $x$ is $\mathrm{Zn}$ concentration. Table I summarizes the findings where Fig. 5 shows the intensity mapping of the $\mathrm{Zn}$ uniformity; it is worth mentioning that the $\mathrm{Zn} \%$ (alloy compound) is the at. \%. To obtain mol $\mathrm{ZnTe} \%$, the values should be multiplied by 2 . In general, the results demonstrate that standard Redlen CZT products have a $10 \% \mathrm{Zn}$ content as intended. The maps also reveal a relative uniform $\mathrm{Zn} \%$ distribution across the CZT detector, a feature that is important in imaging applications and highenergy resolution gamma spectroscopy.

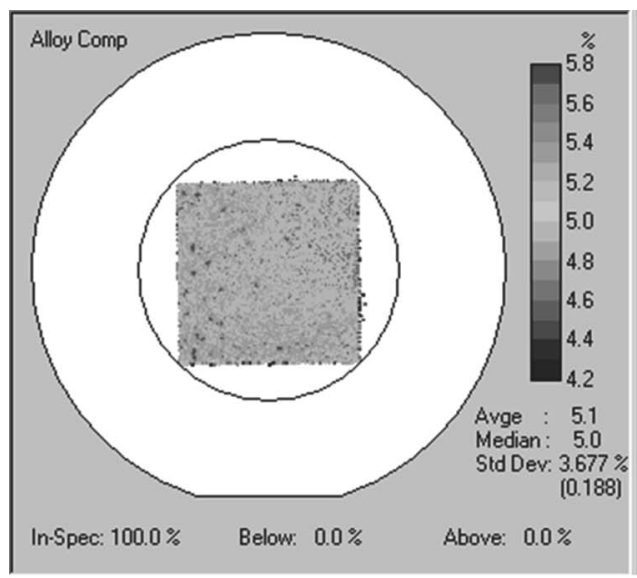

a)
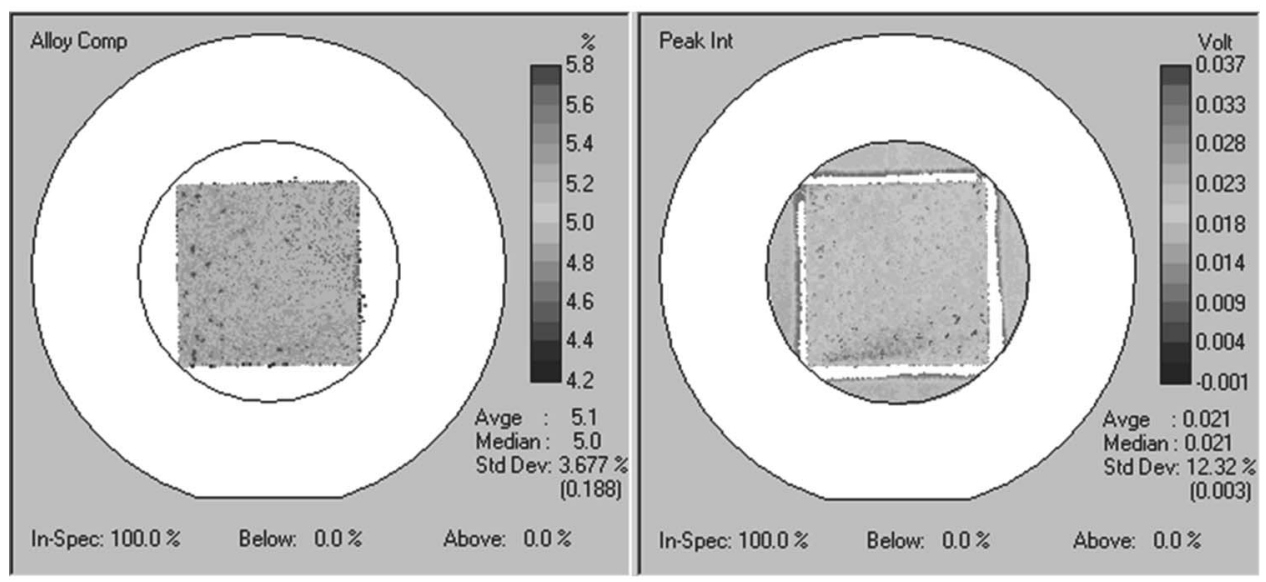

b)
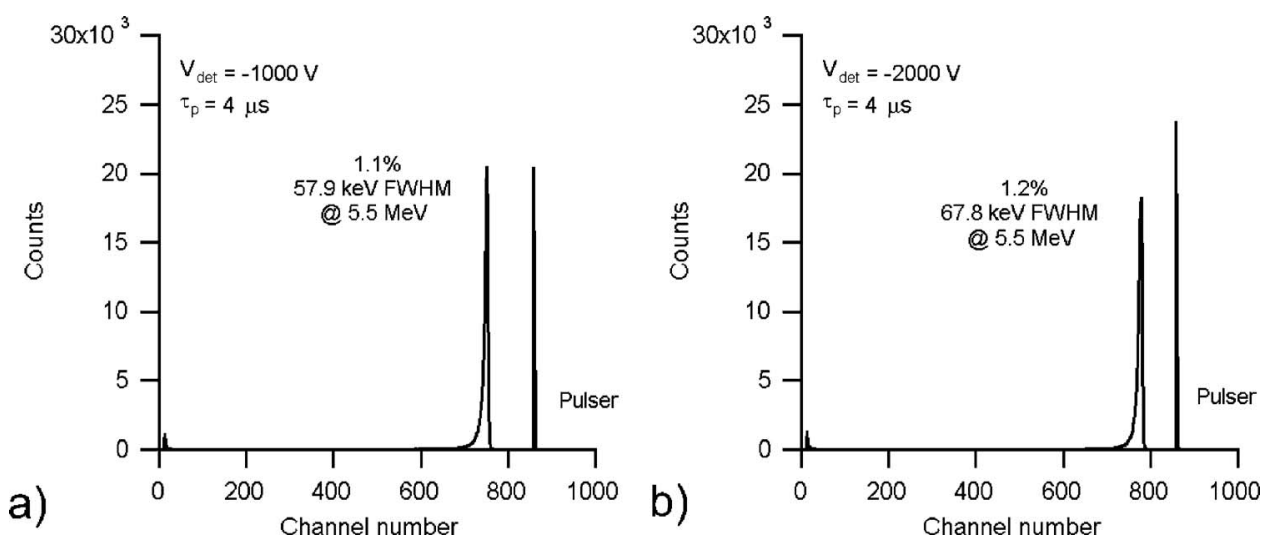

FIG. 5. RT-PL mapping of $20 \times 20$ $\times 5 \mathrm{~mm}^{3}$ CZT crystal: (a) upper face ( $A$ face) and (b) lower face ( $B$ face).

FIG. 6. ${ }^{241} \mathrm{Am}$ alpha-particle spectra obtained with a Redlen $10.8 \times 10.8$ $\times 10 \mathrm{~mm}^{3}$ planar detector at a field of about (a) $1000 \mathrm{~V} / \mathrm{cm}$ and (b) $2000 \mathrm{~V} / \mathrm{cm}$. 


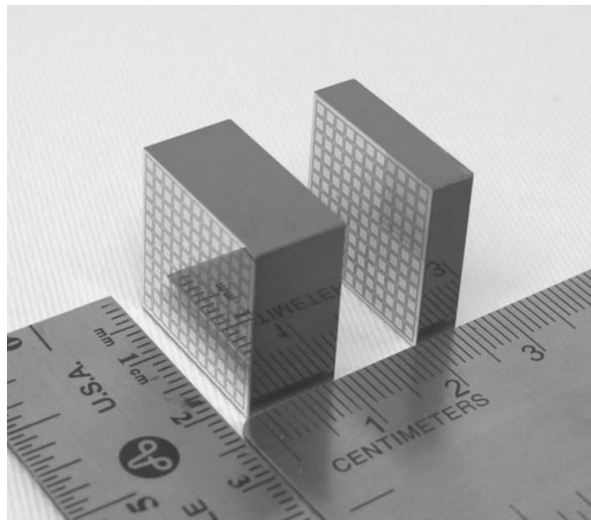

FIG. 7. A comparison of the standard $20 \times 20 \times 5 \mathrm{~mm}^{3}$ vs $20 \times 20$ $\times 10 \mathrm{~mm}^{3}$ monolithic CZT detector.

\section{Electron-mobility lifetime via alpha-particle measurement}

The mobility-lifetime product was carried out on a $10.8 \times 10.8 \times 10 \mathrm{~mm}^{3}$ sample at LBNL using alpha-particle measurements. This method is a well known and effective tool for studying the uniformity of electron mobility lifetime $(\mu \tau) e$ in CZT material. The details of this technique are described elsewhere. ${ }^{5,6}$

Figure 6 shows the alpha-particle spectra obtained from the 10-mm-thick material, exhibiting a relatively uniform electron transport. The obtained $(\mu \tau) e$ value is $\sim 1.3$ $\times 10^{-2} \mathrm{~cm}^{2} / \mathrm{V}$, consistent with the typical $(\mu \tau) e$ values of our standard $5 \mathrm{~mm}$ product. ${ }^{2}$ This exceptional level of $(\mu \tau) e$ in THM grown CZT has been consistently confirmed by several groups including U. Michigan, LBNL, and BNL. ${ }^{7}$

\section{SPECTRAL PERFORMANCE}

To evaluate the performance of the 10 -mm-thick detectors, several tiles were fabricated into pixellated detectors with nominal $X Y Z \sim 10 \times 10 \times 10$ and $20 \times 20 \times 10 \mathrm{~mm}^{3}$. Figure 7 compares the current pixellated $10 \mathrm{~mm}$ vs the $5 \mathrm{~mm}$ thick ones. The above-mentioned pixellated detectors all have $2.46 \mathrm{~mm}^{2}$ pixels and $460 \mu \mathrm{m}$ interpixel gaps. The detectors were evaluated in-house and at several laboratories in Europe and the United States for validation.

This configuration was chosen solely for convenience in fabricating and testing because the existing standard electrode configuration of our product has the same size pixels and interpixel gap. It is noteworthy that the size of the pixel metal contact in this configuration is $2 \mathrm{~mm}$ or roughly $20 \%$ of the detector's thickness while the pixel size of $2.46 \mathrm{~mm}$ constitutes roughly $25 \%$.

This discrepancy illustrates that the size of the fabricated pixel and road (interpixel gap) are not optimized for the device/electrode aspect ratios considering that the device is to be operated with the small pixel effect. ${ }^{4}$ However, even with this limitation, we still obtained an average pixel response around $2 \%$ FWHM for ${ }^{137} \mathrm{Cs}$ at $662 \mathrm{keV}$ without the use of any signal-processing correction. The best spectrum achieved was near $1 \%$ shown in Fig. 8. The spectra were obtained on a standard MCA system at room temperature with typical operating voltages of only $500-800 \mathrm{~V}, 0.5 \mu \mathrm{s}$ shaping time and $120 \mathrm{~s}$ lifetime. A collimator of $1.5 \mathrm{~mm}$ diameter was employed to minimize noise due to multipixel events and charge loss in the interpixel gap region. Under these same conditions, an energy resolution of $2.6 \%$ can be achieved with Co 57 at $122 \mathrm{keV}$ (Fig. 9).

The fact that we recorded a good response from $10.5 \mathrm{~mm}$ detectors at only $500-800 \mathrm{~V}$ bias (i.e., $50-80 \mathrm{~V} / \mathrm{mm})$ is a good indication of a very high $(\mu \tau) e$ value. By using the University of Michigan's $(\mu \tau) e$ method of estimation, ${ }^{8}$ we verified in-house that these values are all $>10^{-2} \mathrm{~cm}^{2} / \mathrm{V}$ s. This value was repeatedly measured at several national laboratories, including LBNL and BNL, as will be discussed later in this paper.

The most important point to mention here is that the $\sim 2 \%$ energy resolution obtained at $662 \mathrm{keV}$ represents values obtained using a nonoptimized detector's configuration and test method. If a good correction mechanism, such as the depth of interaction method is applied on this same 10 -mm-thick material, an energy resolution below $1 \%$ at $662 \mathrm{keV}$ can be achieved, with the possibility of approaching

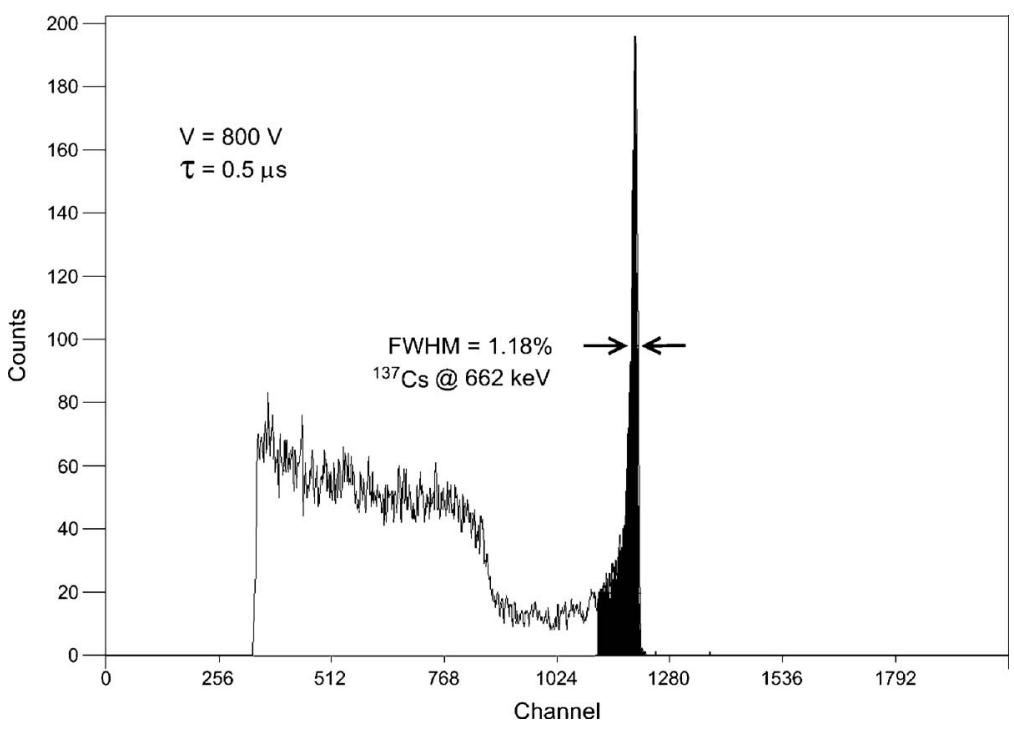

FIG. $8 .{ }^{137} \mathrm{Cs}$ response, $1.18 \%$ FWHM, of a single pixel from $20 \times 20 \times 10.5 \mathrm{~mm}^{3}$ monolithic pixellated detector (pixel size $=2.46 \mathrm{~mm}$ ) without any additional signal correction. 


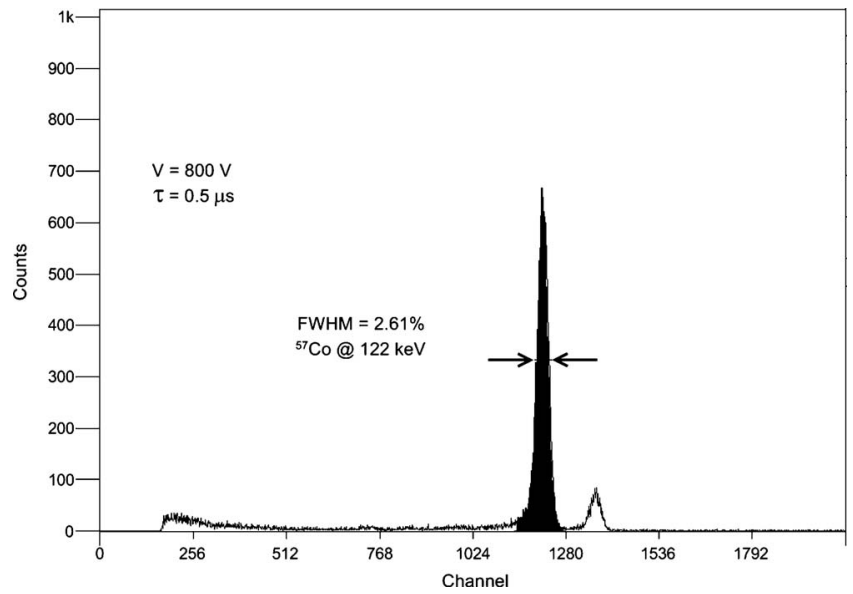

FIG. 9. Room temperature ${ }^{57} \mathrm{Co} 122 \mathrm{keV}$ response of a single pixel from $11 \times 11 \times 10.5 \mathrm{~mm}^{3}$ monolithic pixellated detector (pixel size $=2.46 \mathrm{~mm}$ ) without any additional signal correction.

$0.5 \%$. The evidence for this statement is quite simple and straightforward and as follows: on behalf of the Danish National Space Center (DNSC), we fabricated from the same quality of CZT material $10 \times 10 \times 5 \mathrm{~mm}^{3}$ detectors configured with a $2.5 \mathrm{~mm}$ pixel size and a $100 \mu \mathrm{m}$ interpixel gap (Fig. 10). The detector's energy resolution was first evaluated in-house using our MCA system and the best energy resolution achieved was 2.3\% FWHM at $662 \mathrm{keV}$. The same detector was sent to DNSC and by applying a depth of interaction correction technique, ${ }^{9-11}$ they recorded an energy resolution as good as $0.73 \%$ on the 5 -mm-thick detector, as shown in Fig. 11. Accordingly, we expect a better result from a 10-mm-thick detector due to better ratio of pixel size/ thickness. This work is now ongoing and being carried out in collaboration with several research groups including the DNSC.

It is noteworthy that an energy resolution below $1 \%$ was previously reported using 11-mm-thick material in BNL's 4 $\times 4 \times 11 \mathrm{~mm}^{3}$ Frisch-Grid device. ${ }^{2}$ The detectors' thicknesses in that configuration were radially cut from a standard 6-mm-thick wafer whereas the current R\&D effort focuses on a 12 -mm-thick wafer so that monolithic $20 \times 20 \mathrm{~mm}^{2}$ or larger detectors can be obtained at $10 \mathrm{~mm}$. With a radial cut, $10 \times 10$ detectors up to $40 \mathrm{~mm}$ thick could be obtained from a $50 \mathrm{~mm}$ diameter wafer.

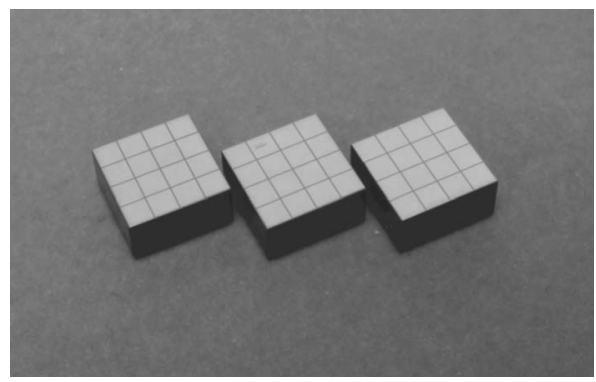

FIG. 10. $10.2 \times 10.2 \times 5 \mathrm{~mm}^{3}$ pixellated detector fabricated for the Danish National Space Center.

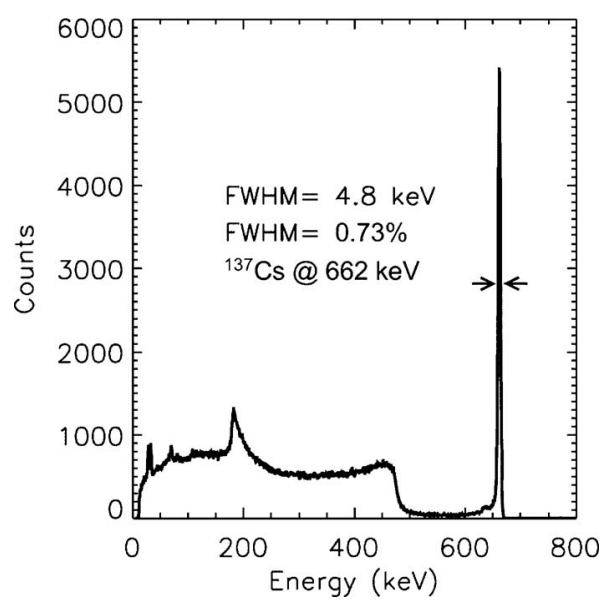

FIG. 11. $662 \mathrm{keV}$ response of a pixel from a detector shown in Fig. 10 measured at DNSC after depth of interaction (DOI) correction: $0.73 \%$ FWHM

\section{CONCLUSIONS}

This work demonstrates our initial successful results in developing larger volume CZT with high-resolution radiation detectors based on the THM growth process. These results suggest that the process is progressing toward optimized crystal growth and wafer processing and the achievement of reliable volume production.

Although more optimization is required, these results clearly demonstrate that with proper design of the devices, and/or additional signal-processing correction, sub-1\% $662 \mathrm{keV}$ energy resolution, possibly approaching $0.5 \%$ is very likely to be achievable in large-volume monolithic pixellated detectors fabricated from crystals of similar quality.

\section{ACKNOWLEDGMENTS}

The authors would like to thank Dr. A. J. Spring Thorpe of the Canadian National Research Council for undertaking the RT-PL measurements, and Brian Zdancewiz and Andrew Macdonald of the Redlen team for technical support.

${ }^{1}$ F. Zhang, Z. He, G. F. Knoll, D. K. Wehe, and J. E. Berry, IEEE Trans. Nucl. Sci. 52, 2009 (2005).

${ }^{2}$ H. Chen, S. A. Awadalla, R. Redden, G. Bindley, A. E. Bolotnikov, G. S. Camarda, G. Carini, and R. B. James, IEEE Trans. Nucl. Sci. 54, 811 (2007).

${ }^{3}$ H. Chen, S. A. Awadalla, R. Redden, G. Bindley, A. Copete, J. Hong, J. Grindlay, M. Amman, J. S. Lee, and P. Luke, IEEE-NNS-MIC-RTSD Conference, San Diego, CA, 29 October-4 November 2006 [IEEE Trans. Nucl. Sci. (unpublished)].

${ }^{4}$ J. E. Toney, T. E. Schlesinger, B. A. Brunnett, R. B. James, J. M. Van Scyoc, M. Schieber, M. Goorsky, and E. Eissler, Nucl. Instrum. Methods Phys. Res. A 380, 132 (1996).

${ }^{5}$ M. Amman, P. N. Luke, and J. S. Lee, IEEE Trans. Nucl. Sci. 47, 760 (2000).

${ }^{6}$ M. Amman, J. S. Lee, and P. N. Luke, Proc. SPIE 4507, 1 (2001).

${ }^{7}$ Redlen internal reports from BNL and LBNL (2005).

${ }^{8}$ Z. He, G. F. Knoll, and D. K. Wehe, J. Appl. Phys. 84, 5566 (1998)

${ }^{9}$ M. A. J. van Pamelen and C. Budtz-Joergensen, Nucl. Instrum. Methods Phys. Res. A 403, 390 (1997).

${ }^{10}$ M. A. J. van Pamelen and C. Budtz-Joergensen, Nucl. Instrum. Methods Phys. Res. A 411, 197 (1998).

${ }^{11}$ I. Kuvvetli, Ph.D. thesis, OerstedDTU, Technical University of Denmark, 2003. 